\title{
Marketplace insertion and professional practice of direct-entry midwives in Brazil: A descriptive study
}

\author{
Narchi Nadia Zanon, Silva Bruna Almeida \\ Direct-Entry Midwifery Program, School of Arts, Sciences and Humanities, University of Sao Paulo, Sao Paulo, Brazil
}

Email address:

nzn@usp.br (Narchi N. Z.), bruna.almeida.silva@usp.br (S. B. Almeida)

\section{To cite this article:}

Narchi Nadia Zanon, Silva Bruna Almeida. Marketplace Insertion and Professional Practice of Direct-Entry Midwives in Brazil: A Descriptive Study. American Journal of Health Research. Vol. 2, No. 6, 2014, pp. 327-333. doi: 10.11648/j.ajhr.20140206.11

\begin{abstract}
Background: One of the strategies that need to be adopted in Brazil is to train and insert a large number of qualified midwives into the job market in order to promote improvements in indicators related to maternal and perinatal health and the model of care. Considering the recent training of midwives and the lack of studies on their absorption into the healthcare system, this study had the objective of verifying the socioeconomic and demographic characteristics of midwives that graduated in 2008 and 2009 from the Direct-Entry Midwifery Program of the University of São Paulo, characterizing and analyzing their academic and professional trajectory, insertion into the job market, and professional practice in midwifery. Method: From November 2012 to March 2013, a descriptive and quantitative investigation was carried out with a population composed of 82 midwives, 41 of them who graduated in 2008 and 41 in 2009. Data were obtained by means of an on-line questionnaire applied electronically and composed of open-ended and closed-ended questions relative to the socioeconomic and demographic identification of the midwives, their academic and professional trajectory, their insertion into the job market, and professional practice in midwifery. Results: Of the total number of former students, $70.7 \%$ agreed to participate in the study and answered the questionnaire. Of this sample, $58.6 \%$ fit into the age bracket of 23 to 27 years, $70.7 \%$ were single, $96.6 \%$ were female, $63.8 \%$ lived in the city of São Paulo, 65.5\% participated in extracurricular activities during their training, $43.1 \%$ participated in specialization or refresher courses after graduating, $51.7 \%$ participated in scientific events, $22.4 \%$ produced scientific studies, and $19 \%$ published in scientific journals. Only $34.5 \%$ indicated working or having worked as a midwife. Conclusions: The results allow the conclusion that, despite the effort to improve their academic and professional trajectory, the first midwives, who graduated in 2008 and 2009, faced great difficulties in getting into a healthcare market which needs skilled human resources and is resistant to the incorporation of new professionals and models of care.
\end{abstract}

Keywords: Human Resources in Midwifery, Work Market, Choice of a Profession, Professional Training

\section{Introduction}

In previous publications [1-4], we and others have described direct-entry midwifery training in Brazil, the challenges faced in this process, its regulation, the difficulties inherent in inserting these new midwives into the healthcare job market, and the need for this type of professional. These earlier publications also called attention to the importance of performing studies on the usefulness of this professional in the Brazilian health system.

This concern stems from the current panorama described in various documents [5-9] that indicate that in Brazil, significant issues relative to maternal and perinatal problems persist and must be addressed by those who formulate public policies in the country. The challenge of the moment is to reverse the following problems:

- A high and stable level of maternal mortality, always above 70 deaths of women for every 100,000 live born infants, especially due to direct obstetric causes and unsafe abortions [6-,8];

- high rates of early neonatal mortality related primarily to problems due to poorly assisted deliveries and excessive medication $[8,9]$;

- elevated and growing rates of prematurity, possibly linked to deliveries even before the $37^{\text {th }}$ gestational week, so that cesarean sections are performed in women who do not go into labor $[8,9]$;

- growing proportions of cesarean sections, which in 2011 reached about $54 \%$ of the approximately three million births in Brazil [5-9]; 
- childbirth medicalization, resulting in high levels in episiotomies, abusive and routine use of oxytocin during the first phase of labor, and low rates of companions during the birth, among other practices not supported by scientific evidence $[5,7,8]$;

- lack of integration between prenatal care and care at birth and during the post-partum period [5,7-9];

- low quality of prenatal care, with a significant occurrence of congenital syphilis, teen pregnancy, and vertical HIV transmission [8];

- high rates of obstetric violence during hospital births due to the over-medicalization of care, which opens the door to violation of the sexual and reproductive rights of women $[8,9]$.

The fact that currently most (98.9\%) deliveries happen in hospitals and are assisted by doctors $(89 \%)$ has not contributed to the expected improvement in care $[8,9]$. On the contrary, it results in unnecessary, expensive, and potentially iatrogenic interventions and inequalities in the provision of care and in outcomes, and does not respect the rights of the women, their families, and newborns, leading to both physical and psychosocial mortality and morbidity.

There are few independent birthing centers in the country; those that do exist are underutilized since they are not well known by the population and not highly regarded by healthcare professionals and systems, while there are many hospital birthing centers dominated by medical professionals, and especially, by the biomedical and interventionist model of care [7-9].

In Brazil, the workforce in the area of maternity care, composed primarily of doctors, includes few nurse-midwives, which according to official data from 2010 only assist in $9 \%$ of deliveries in hospitals [8]. The Brazilian Association of Midwives and Nurse-Midwives [Associação Brasileira de Obstetrizes e Enfermeiros Obstetras] (ABENFO) estimates that there are at most 10,000 nurse-midwives in the country, with no registry or research confirming this fact nor indicating the percentage that work only in midwifery care. Case studies from Brazil and China presented in the 2014 Midwifery Lancet Series [10] show the consequences of economic development in settings in which midwives have been marginalized or excluded from the healthcare system. The case of Brazil suggests that a focus on improvement of a system of health care can result in a reduction in maternal and perinatal mortality and morbidity. Even so, without the balancing effect of the full spectrum of midwifery care, this strategy has also resulted in the maternal and perinatal problems presented.

Recent changes in public policies [11] related to the incentive for the creation and accreditation of organized midwifery-led birthing centers for low-risk deliveries have still not resulted in changes in this scenario. To reintroduce nurse-midwives and/or midwives into the healthcare system is an important strategy to reduce mortality, morbidity, and unnecessary interventions [10]. Midwives are also important to implement woman-centered and evidence-based care in order to promote and advocate for women's sexual and reproductive rights.

Evidence from successful practices in other countries shows that models of care involving midwives are associated with improvements in the health and well-being of women and newborns. From the perspective of health promotion, midwives can collaborate in the constitution of an effective network of care, under the basic premise of humanized attention based on scientific evidence in order to improve the experience of the women and their families in the process of pregnancy, childbirth, and post-partum. However, this only occurs when a large number of midwives are in actual practice, and furthermore, in a social scenario in which they are distinguished as members of a respected and attractive regulated profession, with guaranteed insertion into the healthcare system [12-16].

Based on this context and with the intention of preparing qualified professionals for the requirements of improved attention to midwifery care, in 2005 the School of Arts, Sciences and Humanities of the University of São Paulo (USP) recreated the Direct-Entry Midwifery Program in order to prepare midwives, trained directly in midwifery instead of first going through nursing training, capable of carrying out all the essential skills in midwifery and aiding in the necessary process of transformation of the maternity care model in the country.

Although official, university-based training of direct-entry midwives (called obstetrizes) in Brazil existed until 1971, it was terminated as the midwifery courses were subsumed by nursing and the direct-entry qualification was eliminated in favor of the education of nurse-midwives. Thus the midwifery profession is regulated by the Law of Professional Exercise of Nursing. Midwives prepared by the new, re-created Direct-Entry Midwifery Program, to date the only such program in the country, are the pioneers of this re-created profession, and thus, face difficulties in entering the work market due to corporative resistance of other health workers, to the unfavorable context of care of non-medical work in midwifery care, and especially to the non-existence of the midwifery model of care in the Brazilian healthcare system [1-3].

This complex scenario of the recent training of direct-entry midwives and the lack of studies on the absorption of this important resource into the healthcare job market highlights the need for this present investigation, the objectives of which are to verify and analyze the socioeconomic and demographic characteristics of the midwives trained by USP during 2008 and 2009, and to characterize and analyze their academic and professional trajectory and insertion into the job market, as well as their professional practice in midwifery.

\section{Method}

\subsection{Study Design and Sample}

This is a quantitative and descriptive study carried out between November 2012 and March 2013 with a population composed of 82 former students of the Direct-Entry 
Midwifery Program, with 41 graduated in 2008 and 41 in 2009. The choice to study this early group of graduates was made based on the assumption that it would take them some years after graduation to integrate themselves into the job market and practice midwifery.

In order to access the study population, information used was provided by the training program of USP and contained name, address, telephone, and e-mail of the graduates, data which were updated in various manners, especially by telephone contacts and social networks.

\subsection{Data Collection}

The instrument used for data collection was composed of an online questionnaire previously tested, perfected and applied electronically. Upon receiving the message by e-mail, the participants were invited to open a link; when accessing it, once they read the presentation of the study and agreed to participate, each subject was automatically directed to the questionnaire composed of open-ended and closed-ended questions relative to:

- Socioeconomic and demographic identification: age, gender, marital status, monthly income, and place of residence;

- Academic and professional trajectory: extracurricular activities during the Midwifery Program, participation in any other course after Midwifery, participation in graduate refresher courses or specialization, participation in scientific events during or after Midwifery, preparation and publication of scientific papers related to Midwifery;

- Insertion into the healthcare job market and professional practice of Midwifery: registration in a professional/trade council, search for employment in Midwifery, work in Midwifery, type of work in Midwifery, and characteristics of the healthcare institution.

\subsection{Data Analysis}

The responses of the participants were identified by numbers produced by the Qualtrics program used to prepare the questionnaire and store data on a spreadsheet where possible duplicate answers could be verified. The results were analyzed by means of descriptive statistics and the responses to the open-ended questions were described by similarity of content.

\subsection{Ethical Approval}

The study was approved by the Ethics in Research Committee of the School of Arts, Sciences, and Humanities at USP, and only graduates who agreed to participate were included by accessing the first page of the survey, which contained the Informed Consent Form that assured the due confidentiality of information.

\section{Results}

Of the 82 former students, $72(87.8 \%)$ accessed the study link. Of these, only $58(70.7 \%)$ agreed to participate, responding to the on-line questionnaire. In this group, 31 (53.4\%) indicated having graduated in 2008, and 27 (46.5\%), in 2009 .

Table 1. Socioeconomic and demographic characterization of the participants.

\begin{tabular}{|c|c|c|}
\hline Characteristics & $\mathbf{N}$ & $\%$ \\
\hline \multicolumn{3}{|l|}{ Age bracket } \\
\hline 23 to 27 years & 34 & 58.6 \\
\hline 28 to 32 years & 16 & 27.5 \\
\hline 33 to 37 years & 6 & 10.3 \\
\hline 43 to 47 years & 1 & 1.7 \\
\hline 48 to 52 years & 1 & 1.7 \\
\hline Total & 58 & 100.0 \\
\hline \multicolumn{3}{|l|}{ Gender } \\
\hline Male & 2 & 3.4 \\
\hline Female & 56 & 96.6 \\
\hline Total & 58 & 100.0 \\
\hline \multicolumn{3}{|l|}{ Marital Status } \\
\hline Single & 41 & 70.7 \\
\hline Married & 11 & 19.0 \\
\hline Stable Union & 5 & 8.6 \\
\hline Divorced & 1 & 1.7 \\
\hline Total & 58 & 100.0 \\
\hline \multicolumn{3}{|l|}{ Monthly wages in $\mathrm{MW}^{*}$} \\
\hline Up to 2 & 5 & 8.6 \\
\hline From 3 to 4 & 27 & 46.6 \\
\hline From 5 to 6 & 14 & 24.2 \\
\hline From 9 to 10 & 1 & 1.7 \\
\hline More than 10 & 1 & 1.7 \\
\hline Does not work & 10 & 17.2 \\
\hline Total & 58 & 100.0 \\
\hline \multicolumn{3}{|l|}{ City of residence } \\
\hline São Paulo & 37 & 63.8 \\
\hline Interior state of São Paulo & 21 & 36.2 \\
\hline Total & 58 & 100.0 \\
\hline
\end{tabular}

* MW $=$ Minimum Wage in $2012=$ approximately US\$310/month

Table 1, which shows data relative to the characterization of the participants, demonstrates that most were between 23 and 27 years of age $(58.6 \%)$, single $(70.7 \%)$, female $(96.6 \%)$, and lived the capital city of São Paulo (63.8\%). Also noted was the fact that 48 graduates $(82.7 \%)$ reported some type of remuneration and work, with an income predominantly between three and four minimum wages (46.6\%).

Table 2, which shows data in reference to the academic and continuing education trajectory of the participants, demonstrates that a large percentage participated in extracurricular activities during their training, such as scientific events $(65.5 \%)$, voluntary internships $(51.7 \%)$, and research $(51.7 \%)$ or extension $(37.9 \%)$ projects. The rationales given for non-participation in these activities are 
related to lack of time, of opportunity, or of interest.

Table 2 also shows that $44.8 \%$ of the participants reported having done another undergraduate course besides Midwifery, such as Nursing, Medicine, Physical Therapy, Advertising, Languages, Gastronomy, Law, and Radio/TV. It was noted that $39.6 \%$ indicated participation in graduate courses, whether for specialization in the area of healthcare $(19.0 \%)$ or in Masters $(10.3 \%)$ and Doctorate $(10.3 \%)$ programs. Only $43.1 \%$ of the subjects reported having participated in refresher or specialization courses after their training in Midwifery. The justifications given for non-participation were related to lack of time, lack of motivation to work in this profession, lack of financial resources, problems with professional registry, or absence of courses that were specific or directed towards midwives.

Table 2. Academic and continuing education trajectory of the participants.

\begin{tabular}{|c|c|c|}
\hline Category & $\mathbf{N}$ & $\%$ \\
\hline \multicolumn{3}{|l|}{ Extracurricular Activity during training } \\
\hline Voluntary Internships & 30 & 51.7 \\
\hline Extension Projects & 22 & 37.9 \\
\hline Research Projects & 30 & 51.7 \\
\hline Scientific Events & 38 & 65.5 \\
\hline Others & 12 & 20.7 \\
\hline Did not respond & 4 & 6.9 \\
\hline Total (more than one response to each question) & 136 & 100.0 \\
\hline \multicolumn{3}{|l|}{ Other graduate course after Midwifery } \\
\hline Yes & 26 & 44.8 \\
\hline No & 32 & 55.2 \\
\hline Total & 58 & 100.0 \\
\hline \multicolumn{3}{|l|}{ Graduate Course } \\
\hline Yes & 23 & 39.6 \\
\hline No & 35 & 60.4 \\
\hline Total & 58 & 100,0 \\
\hline \multicolumn{3}{|l|}{ Type of Graduate Course } \\
\hline Specialization & 11 & 19.0 \\
\hline Master's & 6 & 10.3 \\
\hline Doctorate & 6 & 10.3 \\
\hline Did not respond & 35 & 60.4 \\
\hline Total & 58 & 100.0 \\
\hline \multicolumn{3}{|l|}{ Refresher Course/Specialization } \\
\hline Yes & 25 & 43.1 \\
\hline No & 33 & 56.9 \\
\hline Total & 58 & 100.0 \\
\hline \multicolumn{3}{|c|}{ Participation in Scientific Event during or after graduation } \\
\hline Yes & 30 & 51.7 \\
\hline No & 25 & 43.1 \\
\hline Did not respond & 3 & 5.2 \\
\hline Total & 58 & 100.0 \\
\hline \multicolumn{3}{|l|}{ Production of a Scientific Study related to Midwifery } \\
\hline Yes & 13 & 22.4 \\
\hline No & 37 & 63.8 \\
\hline Did not respond & 8 & 13.8 \\
\hline Total & 58 & 100.0 \\
\hline \multicolumn{3}{|l|}{ Publication of a Scientific Study related to Midwifery } \\
\hline Yes & 11 & 19.0 \\
\hline No & 39 & 67.2 \\
\hline Did not respond & 8 & 13.8 \\
\hline Total & 58 & 100.0 \\
\hline
\end{tabular}

Additionally, Table 2 shows that $51.7 \%$ reported having participated in scientific events as auditor, organizer, or lecturer, while $22.4 \%$ mentioned having produced some type of scientific paper related to Midwifery, and $19 \%$ had also published studies in scientific journals.

According to Table 3, which shows data relative to job market insertion, $12.1 \%$ of the participants did not register with the Federal Council of Nursing, a primary condition for working in the area. The rationale for this was the fact that they dropped out of the career or encountered resistance on the part of the Council regarding completing the registry. It can also be noted that only $34.5 \%$ of the former students indicated working or having worked as midwives in predominantly hospital environments $(31 \%)$. We point out, however, that $50 \%$ of the graduates had never worked in their area of training, choosing to do another graduate course or work in other areas.

As to work sector, the 20 former students who reported working or having worked as midwives indicated that this had been done in assisting women during the process of labor and delivery $(27.6 \%)$, in assisting women or newborns during the post-partum period (19\%), or in activities to promote and educate in health and prenatal care $(20.6 \%)$.

Of the participants who were able to work in the specific profession, some reported having left it during some periods for reasons related to employment changes $(6.9 \%)$, the need for dedication to studies (3.4\%), and especially, rejection by other professionals who were against their hiring or permanence on the job (10.3\%).

Of the $50 \%$ of former students who reported never having worked in their area of training, $69 \%$ said they had entered the work market in other activities, such as administrative services in telemarketing firms, hospital administration, tax auditing, or others.

Table 3. Insertion of the participants into the work market.

\begin{tabular}{|c|c|c|}
\hline Category & $\mathbf{N}$ & $\%$ \\
\hline \multicolumn{3}{|c|}{ Professional Registration in the Nursing Council } \\
\hline Yes & 43 & 74.1 \\
\hline No & 7 & 12.1 \\
\hline Did not respond & 8 & 13.8 \\
\hline Total & 58 & 100.0 \\
\hline \multicolumn{3}{|c|}{ Works/Worked as a Midwife } \\
\hline Yes & 20 & 34.5 \\
\hline No & 29 & 50.0 \\
\hline Did not respond & 9 & 15.5 \\
\hline Total & 58 & 100.0 \\
\hline \multicolumn{3}{|c|}{ Type of institution where they work/worked as a Midwife } \\
\hline Public & 6 & 10.3 \\
\hline Private & 12 & 20.7 \\
\hline Philanthropic & 1 & 1.7 \\
\hline Other & 1 & 1.7 \\
\hline Did not respond & 38 & 65.6 \\
\hline Total & 58 & 100.0 \\
\hline \multicolumn{3}{|c|}{$\begin{array}{l}\text { Characteristic of the Institution where they work/worked } \\
\text { as Midwife }\end{array}$} \\
\hline Hospital & 18 & 31.0 \\
\hline Ambulatory & 1 & 1.7 \\
\hline Other & 1 & 1.7 \\
\hline Did not respond & 38 & 65.6 \\
\hline Total & 58 & 100.0 \\
\hline
\end{tabular}




\section{Discussion}

There are few follow-up surveys of former students that can serve as a basis for discussion of the data presented. One study [17], unfortunately not published, carried out at the beginning of 2008 by a Scientific Initiation student of the Midwifery Program, already predicted that there would be problems for absorption of midwives by the job market resulting from the lack of understanding of the innovative potential of the new profession, lack of public and private investments in hiring a greater number of professional midwives, the novelty of the profession in Brazil, and the generalized lack of value given by the Brazilian society to healthcare work by the non-medical professional, among other factors. This shows that at that time, even before the first class graduated, the students were already preparing for the difficulties of a market closed both to the insertion of a new healthcare professional and to the possibility of greater participation of midwives in midwifery care.

A qualitative study carried out in 2010 by a teacher of the Midwifery Program, with the objective of understanding the academic experience and professional insertion of 24 former students graduated in 2008 , shows that only $17 \%$ of them were working in midwifery care; the rest had gone back to studying in another undergraduate or graduate course, or were involved in activities not related to their training. This occurred due to the difficulties they faced in obtaining professional registration or in freely working after the registry, since the impediments to hiring of midwives were very strong [18].

Comparisons regarding results of the present investigation can be made with some studies that describe the job market in healthcare in Brazil [19-22]. The first is related to the feminization of healthcare professions, especially those related to care, such as Nursing, and consequently, Midwifery: $96.6 \%$ of the former students of this study are women.

Another characteristic mentioned by the authors cited [19-22] is related to a greater urban concentration of healthcare professionals, a problem to be faced by healthcare decision-makers for the area of human resources in health; $68.3 \%$ of the participants in the present investigation lived in São Paulo, a capital that concentrates the greatest number of services and professionals, i.e., it is a saturated market and therefore poorly receptive to the integration of new professions, especially those who can compete in midwifery care.

In addition to facing obstacles related to a lack of knowledge of the profession, corporative resistance, and the existence of a biomedical and interventionist care model, the former students of the Direct-Entry Midwifery Program also faced difficulties relative to the recent characteristics of the healthcare sector in the country, marked by lowered salaries, unemployment, high turnover, and an increase in precarious work relations [22].

For Silva et al.[20] and Varella et al.[21], overcoming these characteristics requires an approximation of the policies of healthcare to the policies for training of healthcare professionals and regulation of the job market and employment, i.e., there needs to be an effective and coordinated integration between universities, public and private health institutions, the Ministry of Labor and Employment, and the Ministry of Health, with the purpose of addressing the true demands of society, something that has not been occurring in Brazil.

Wermelinger et al. [22] point out that overcoming the frustration of the graduates includes surpassing the difficulties of occupying a job position immediately after concluding the course. Unfortunately, no course or training of any type or level carries with it the key to this victory (i.e., occupying a work position soon after training), primarily due to the disproportion between education and the market. This discrepancy is caused by mutual lack of knowledge of interests (between instructors and the market), of needs, and of distancing in order to develop joint actions in partnership.

Unemployment in the area of health is a problem that coexists in contradiction to the scarcity of professionals, especially those with specific skills such as the case of nurse-midwives and midwives in Brazil. According to Silva et al. [20], the lack of efficacy in the planning policies of the healthcare workforce in Latin American countries has led to underemployment and a search for other occupations to supplement income, even to Nursing, a profession that traditionally had not been facing these problems.

This was probably the scenario found by the former students of the Direct-Entry Midwifery Program who, despite seeking to improve their training during or after graduation, as is shown on Table 2, did not get employment in the area. It is possible that some of those who did not seek registration with the Professional Council (12.1\%) or even employment in midwifery (13.8\%) already had other professional intentions or had not adhered to the project of becoming midwives. Others $(50 \%)$ probably gave up the profession because they were rejected or because they felt insecure and uncomfortable with the relations they found in the work environment.

Those $34.5 \%$ who managed to meet the challenge, accepting work in the area even if in an irregular and financially unstable manner, possibly acquired more experience and maturity for decision-making and consolidation of the profession. Analysis of the answers given to the open-ended questions shows that this portion of former students was the one most involved in extracurricular activities during their training, whether by participation in research or extension projects of service to the community, which ratifies the importance of these activities in the process of training professionals and citizens aware of their duties towards human health care and the transformation of the Brazilian maternal-childhood care model.

As the results show, many ex-students continued their studies, whether in graduate programs or specialization in the area. Some of these are even already connected to the Direct-Entry Midwifery Program as professors or supervisors in clinical practice and internships. In this way, dialogue and integration between students and those professors or supervisors are established, which also strengthens the training of midwives by the Direct-Entry Midwifery Program. 
Many of the primary barriers that midwives face in the world, described in the UNFPA document [15] that points out the importance of countries investing in midwives, are present in Brazil. In this article we highlight those related to the lack of knowledge of the population as to the role of midwives in care, the insufficient number of skilled professional midwives, the lack of theoretical and clinical updating of physicians, nurses, and midwives, the lack of public and private investment in the permanent training and education of professionals and improvement of services, and low salaries, especially for nurses and midwives. That document also cited difficulties related to the choice that the professionals make for less conflicting and more lucrative activities other than midwifery, the lack of incentives and policies for increasing human resources in public and private healthcare services, rivalries and conflicts that exist between physicians and nurses as well as among nurses and midwives, and the lack of professional unity and strengthening of professional midwives, and finally, the lack of partnership between midwives and the women in order to enjoy greater recognition.

\section{Conclusions and Final Considerations}

We conclude that the objectives of the study were met in the sense that there was expressive participation of the midwives graduated by USP during 2008 and 2009, and it was possible to trace a panorama of their socioeconomic and demographic characteristics, as well as to analyze their academic and professional trajectory and insertion into the job market with their professional work in midwifery.

The results allow the conclusion that, despite the performance in improving their academic and professional trajectory, midwives graduated during 2008 and 2009 faced great difficulties in entering the work market which is so poor in human resources and so resistant to changes. For this reason, only a small percentage of the participants in this study managed to meet the challenge and find and accept work in the area, even if under irregular and unstable financial conditions, acquiring more experience and maturity for decision-making and consolidation of the profession in Brazil.

We must emphasize the need for change in configuration of the Brazilian obstetric and midwifery model of care. It needs to come closer to the cultural and social environments of the women and their families, and move towards respect for human rights and facilitation of the normal physiology of birth, which will result in changes. This will happen as a great number of non-medical professionals, such as midwives, are valued and absorbed into the Brazilian healthcare system.

Still unknown is if the percentage of midwives that are finding their space in the work market has been increasing over the last few years, and if a greater number of former students have effectively faced the challenges of the profession. For this, more research is needed, such as accompanying midwives trained by USP. By knowing the professional trajectory of these midwives, one can reflect on the characteristics inherent to the job market and the changes perhaps implanted in maternal assistance and issues relative to the teaching of Midwifery that were not covered in this study.

It is important to add that the inclusion of midwives in the job market is defended not only by those involved in their training, but especially by various governmental and non-governmental entities of the Brazilian society and by researchers involved in the arena of women's health.

In this process, we point to the necessity of professional organizations, essential for making a profession viable. For this reason, in 2011, midwives founded the Association of Midwives (Associação de Obstetrizes), an organization independent from ABENFO and which, along with activists and organized movements, has been taking a stand socially and politically in order to help midwives gain entrance into the healthcare job market, and especially, social visibility for the work they carry out.

Midwives trained by USP today count on the support and representation of this new organization that is taking an active role in social and political arenas that are fundamentally necessary for understanding of the innovative potential of this profession in maternal care in the country. Additionally, this process of recognition is already present in Brazilian society; empirically, one can already observe that midwives have gained better opportunities for work in maternity hospitals, birthing centers, and public or private birthing homes where they have generated slow yet ongoing changes in the model of care, since they are more committed to internalizing and practicing a true midwifery model of care. These direct-entry midwives have increased their spectrum of action offering autonomous services to women and families, such as in planned home births, with a percentage that has been gradually increasing in the country.

We hope that this transformational movement, in which midwives play an essential role, will continue to gain momentum in order to guarantee better healthcare alternatives for Brazilian women.

\section{References}

[1] Gualda DMR, Narchi NZ, Campos EA. Strengthening midwifery in Brazil: Education, regulation and professional association of midwives. Midwifery 2013, 29: 1077-81.

[2] Narchi NZ, Silva LCFP, Gualda DMR, Bastos MH. Reclaiming direct-entry midwifery training in Brazil: context, challenges and perspectives. Midwifery 2010, 26: 385-388.

[3] Narchi NZ, Silva LCFP, Gualda DMR. Midwifery training in Brazil: context, challenges and perspectives. Saúde $e$ Sociedade 2012, 21(2): 510-9 [online in Portuguese].

[4] Narchi NZ, Cruz EF, Gonçalves R. The role of midwives and nurse-midwives in promoting safe motherhood in Brazil. Ciência \& Saúde Coletiva 2013, 18(4): 1053-62 [online in Portuguese].

[5] Brasil. National Research of Demographic and Women and Children Health - 2006: dimensions of the reproductive and child health. 2009. [http://bvsms.saude.gov.br/bvs/publicacoes/pnds_crianca_mul her.pdf] [online in Portuguese]. 
[6] Brasil. Health Brazil 2009: an analysis of the health situation and the national and international agenda of health priorities. 2010.

[http://portal.saude.gov.br/portal/arquivos/pdf/SAUDE_BRAS IL_2009_COLETIVA.pdf] [online in Portuguese].

[7] Brasil. Health Brazil 2011: an analysis of health status and women health surveillance. 2012. [http://portalsaude.saude.gov.br/portalsaude/texto/9461/783/sa ude-brasil-2011-uma-analise-da-situacao-de-saude.html] [online in Portuguese].

[8] Victora CG, Leal MC, Barreto ML, Schmidt MI, Monteiro CA. Health in Brazil. The Lancet Series. Rio de Janeiro: Fiocruz; 2011.

[http://189.28.128.100/dab/docs/geral/the_lancet_05_2011.pdf] [online in Portuguese].

[9] Victora CG, Barros AJD, Axelson H, Bhutta ZA, Chopra M, França GVA, Kerber K, Kirkwood BR, Newby H, Ronsmans C, Boerm JT. How changes in coverage affect equity in maternal and child health interventions in 35 Countdown to 2015 countries: an analysis of national surveys. Lancet, 2012. [http://dx.doi.org/10.1016/S0140-6736(12)61427-5].

[10] Renfrew MJ, McFadden A, Bastos MH, Campbell J, Channon A, Cheung NF, Silva DRAD, Downe S, Kennedy HP, Malata A, McCormick F, Wick L, Declercq E. Midwifery and quality care: findings from a new evidence-informed framework for maternal and newborn care. Lancet 2014; published online June 23. http://dx.doi.org/10.1016/S0140-6736(14)60789-3.

[11] Brasil. Establishes guidelines for the implantation and accreditation of the Center for Normal Delivery [Centro de Parto Normal] (CPN), within the scope of the National Unified Health System [Sistema Único de Saúde] (SUS), to care for women and newborns at the time of birth, according to the Delivery and Birth Component of the Stork Network [Componente Parto e Nascimento da Rede Cegonha], and dictates on the respective financial incentives for investment, expenses, and monthly costs. Brasil: Ministério da Saúde, $\begin{array}{llll}\text { Portaria } & \mathrm{n}^{\circ} . & 904 . & 2013 .\end{array}$ $<$ http://bvsms.saude.gov.br/bvs/saudelegis/gm/2013/prt0904_2 9_05_2013.html > [on-line in Portuguese]

[12] Inter-American Commission on Human Rights. Access to maternal health services from a human rights perspective. OEA; 2006. [http://cidh.org/women/SaludMaterna10Sp/SaludMaterna2010 .pdf] [online in Spanish]

[13] World Health Organization. Safe motherhood needs assessment - guidelines. Geneva: WHO; 2001. [http://www.who.int/reproductivehealth/publications/maternal _perinatal_health/rht_msm_96_18/en/index.html]
[14] World Health Organization. Making Pregnancy Safer: the critical role of the skilled attendant. Geneva: WHO/ICM/FIGO; 2004.

[http://www.who.int/making_pregnancy_safer/documents/924 1591692/en/index.html]

[15] United Nations Population Fund. Towards MDG 5: Scaling up the capacity of midwives to reduce maternal mortality and morbidity. Workshop Report. New York: UNFPA; 2006. [http://www.unfpa.org/webdav/site/global/shared/documents/p ublications/2006/midwives_mm.pdf]

[16] United Nations Population Fund. Maternal Mortality Update 2006. Expectation and Delivery: Investing in Midwives and Others with Midwifery Skills. New York: UNFPA; 2007. [http://www.unfpa.org/webdav/site/global/shared/documents/p ublications/2007/mm_update06_eng.pdf]

[17] Jesus GM. Teachers and students expectation of the Direct-entry Midwifery Program; 2008 (unpublished).

[18] Trintinália MM. Characterization and professional inclusion of former students from the undergraduate program in midwifery at the University of São Paulo. Dissertation. University of São Paulo, Nursing School; 2011. [http://www.teses.usp.br/teses/disponiveis/7/7141/tde-170820 11-103213/publico/Maryam_Michelle_Jarrouge_Trintinalia.p df] [online in Portuguese]

[19] Machado MH, Oliveira ES, Moyses NMN. Tendencies of the work model in healthcare in Brazil. In: Work in healthcare: quantitative and qualitative approaches. Volume 2. Rio de Janeiro: CEPESC, UERJ; 2011:103-116.

[20] Silva KL, Sena RR, Grillo MJC, Gandra ED, Silveira MR. Expansion of undergraduate courses in nursing: dilemmas and contradictions facing the labor market. Rev Esc Enferm USP 2013, 47(5): 1219-26. [http://www.scielo.br/scielo.php?script=sci_arttext\&pid=S008 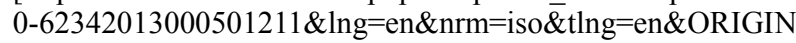 $\mathrm{ALLANG}=\mathrm{en}]$

[21] Varella TC, Pierantoni CL. The nursing profession in Brazil: a job market under transformation? In: Work and education in health in Mercosul. Brasília: Ministério da Saúde; Rio de Janeiro: Europa; 2008:123-152.

[22] Wermelinger M, Machado MH, Amâncio Filho A. 2007. Professional educational policies: references perspectives. Ensaio: Aval Pol Públ Educ 2007, 15(55), 207-222. $<$ http://www.scielo.br/scielo.php?script=sci_arttext\&pid=S01 04-40362007000200003> [on-line in Portuguese] 